\title{
A Semi Automated Method for Laminated Sediments Analysis
}

\author{
Mapathe Ndiaye $^{1}$, Eric Davaud ${ }^{2}$, Daniel Ariztegui ${ }^{2}$, Meissa Fall ${ }^{1}$ \\ ${ }^{1}$ Laboratoire de Mécanique et Modélisation, Université de Thiès, Thiès, Senegal \\ ${ }^{2}$ Section of Earth and Environmental Sciences, University of Geneva, Geneva, Switzerland \\ Email: mapathe.ndiaye@univ-thies.sn
}

Received November 8, 2011; revised December 23, 2011; accepted January 24, 2012

\begin{abstract}
We developed a software performing laminae counting, thickness measurements, spectral and wavelet analysis of laminated sediments embedded signal. We validated the software on varved sediments. Varved laminae are automatically counted using an image analysis classification method based on K-Nearest Neighbors (KNN) algorithm. In a next step, the signal corresponding to varved black laminae thickness variation is retrieved. The obtained signal is a good proxy to study the paleoclimatic constraints controlling sedimentation. Finally, the use of spectral and wavelet analysis methods on the variation of black laminae thickness revealed the existence of frequencies and periods which can be linked to known paleoclimatic events.
\end{abstract}

Keywords: Varve; Laminated Sediment; K-Nearest Neighbor; Signal; Time-Series; Spectral Analysis; Wavelet Analysis

\section{Introduction}

Laminated sediments often present alternating lamina that can be attributed to seasonally driven oscillation between two or more sedimentary phases [1]. Laminae deposition is linked to sedimentary process, which can be periodic or not. Existing period ranges through magnitudes varying from some hours for a tidal channel deposit [2] to millions years for some laminated sediments $[3,4]$.

Laminated sediments in geosciences provide high-resolution data and therefore, a good proxy for depositional/climatic changes studies [5].

The facies change and the associated thickness variation can be used to generate high-resolution time-series revealing the rhythm of climatic variation [6] or sedimentary inflow rates [7].

When the depositional period of a sequence of laminae is known, the duration of the stratigraphic log can be deduced by counting the number of sequences. Moreover, when the thickness or compositional variation of the laminated sediment in time is available, it can be studied using time-series analysis to highlight existing cyclic events.

Laminated sediments can be counted manually when the number of lamina is low, but counting becomes tedious as the number of lamina increases. This motivated the implementation of semi automated analysis methods based on color properties observed on core photographs, x-ray radiographs, etc. [8-12]. In the particular case of varved sediments, it is often easy to differentiate black from white laminae. Nevertheless, difficulties can arise from the existence of trend or color change among the laminae of the same facies induced by the acquisition material itself or by uneven lightening during acquisition. These problems motivated the implementation in this work of complementary semi-automated analysis methods combing image analysis and signal processing methods.

\section{Material and Method}

We developed a software named Strati-signal using the Java language. Strati-signal is dedicated to stratigraphic signal analysis. Indeed, in addition to laminated sediments analysis methods presented here, Strati-signal contains many other stratigraphic signal analysis methods but they are out of the scope of this paper.

Strati-signal and its user guide are available for download as freeware at:

http://archive-ouverte.unige.ch/vital/access/manager/R epository/unige:717.

We carried out a case study on the varves of CAR 99-10P Section Number 5 of Lago Cardiel sedimentary core ([13,14]) (Figure 1). The cores Number 1 to 4 were not used because of the particularity induced by high presence of turbidite deposits. The Lago Cardiel is located 


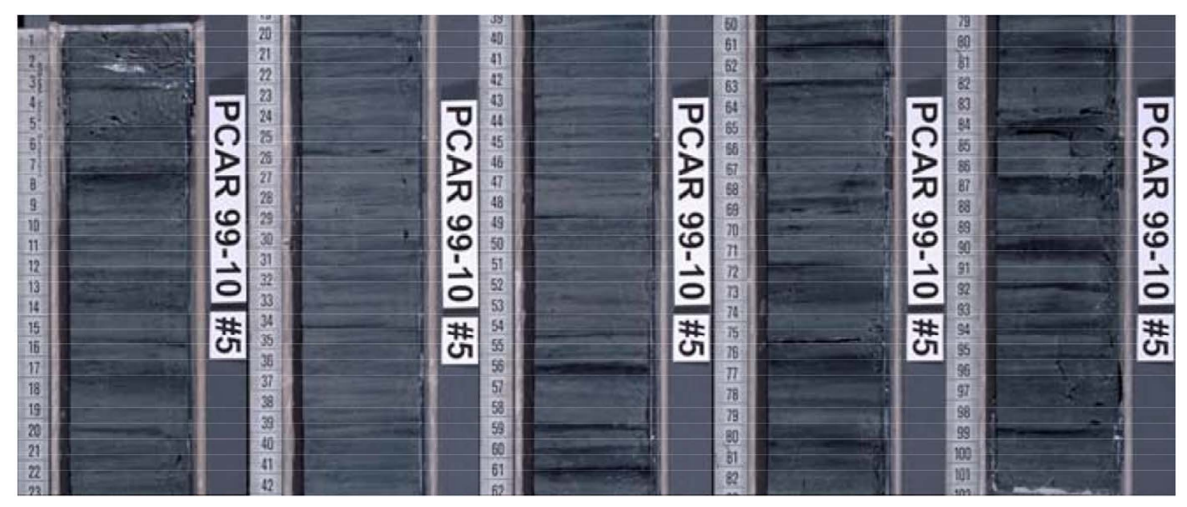

Figure 1. Section 5 of Lago Cardiel Core CAR 99-10P. For easy handling of the image, the section is subdivided into 5 pieces of about $20 \mathrm{~cm}$ length. Note that each two consecutive pieces overlap perfectly.

$49^{\circ} \mathrm{S}$ on the Patagonian plateau of Argentina. The varved sediments present white laminae alternating with iron oxyhydroxyde rich black laminae. The oxyhydroxyde materials input is mostly linked to the wind system. Each couplet of black/white laminae corresponds to one-year deposit ([13,15]). These varved sediments are thus good proxy for past changes in wind intensity of the region.

The analysis of the laminated sediment is performed through three steps:

The first step consists in raw signal extraction. In this step, data corresponding to CIE Lab color variation through the core image is retrieved. The signal is obtained combining data from one or more scan lines with user defined size and position (Figure 2).

During the raw signal extraction, multiplying scan lines avoid artifacts on the source image. After the setup of the scan lines, the user hits the "get" button in the toolbar to extract the signal (Figure 3).

In the second step of the analysis, the varved laminae are counted. Laminae counting is a classification process based on the K-nearest neighbor (K-NN) algorithm [16]. The principle is to classify laminae, based on the closest training samples in a user-predefined feature space.

The three dimensions of the feature space correspond to three signals retrieved from each one of the three CIE Lab (or RGB) channels of the crop image. The learning samples are plotted in the feature space. The quality of learning step can be controlled visualizing each plane of the feature space (Figure 4(E)). The operator can use a list to show each one of the three planes forming the feature space. If learning step is well performed, two groups of samples will be formed in the feature space corresponding respectively to white and black laminae.

The training samples are got by successive mouse clicks on a user-desired part of the synthetic image (Figure 4(B)) to pick significative samples of white or black laminae. In other words, the user indicates successively to the classifier what a black lamina and a white lamina is.

When the user hits the "Apply" button (Figure 4(F)), the classification is performed. Classification gives the number of lamina for each type (black or white) and the thickness variation. The signal corresponding to black lamina thickness which is linked to the past wind intensity, can be explored using spectral or wavelet analysis.

\section{Results}

\subsection{Varved Laminae Counting}

The number of lamina is shown in a report and the thickness variation in a table.

According to the nature of the input image, some varved laminae should be misclassified. Misclassification occurs when a white lamina is classified as a black one or vice versa. Misclassification can be visually appreciated from the classification results windows (Figure 5(A1) and (A2)) comparing the source image (left) with the synthetic image made from classification results (right).

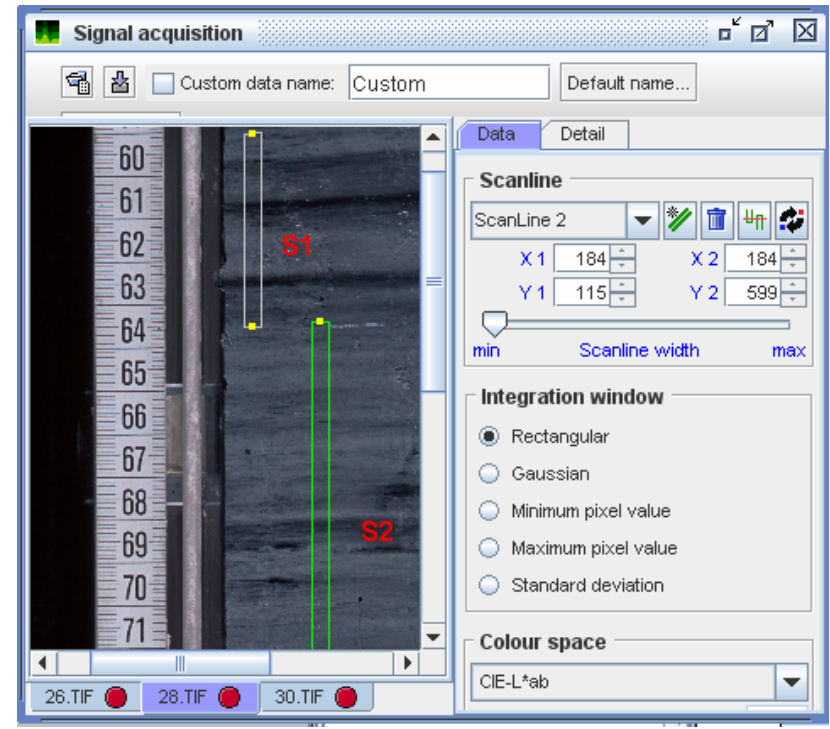

Figure 2. Example of raw signal extraction from two scan lines (S1 and S2). Scan lines can be managed (add, remove, modify) using tools on the right panel. 


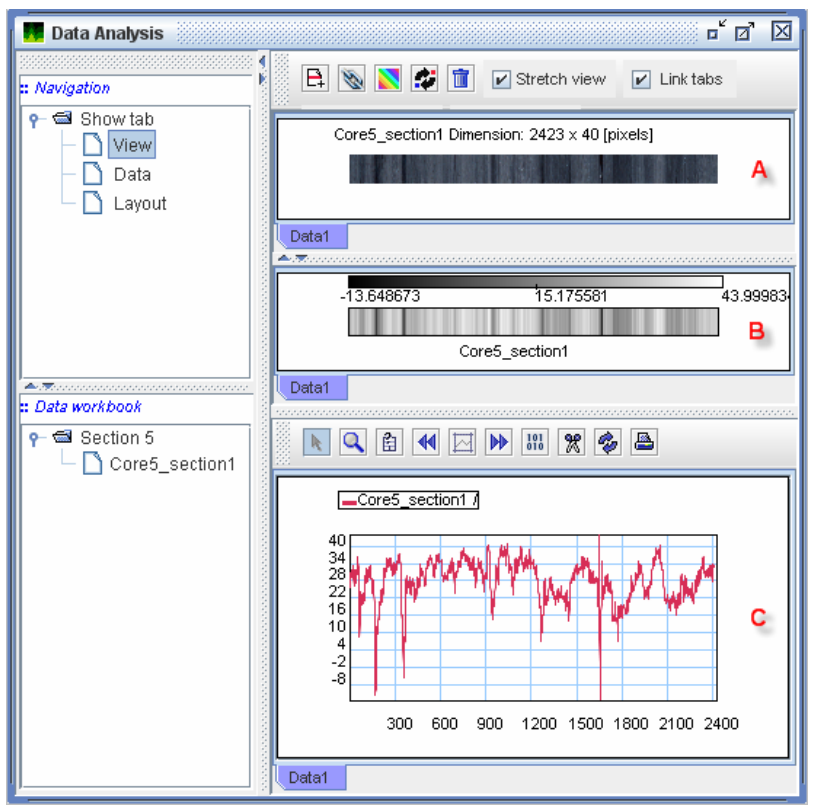

Figure 3. Screenshot showing the extracted raw signal (C), a synthetic image from the signal (B) and a crop image corresponding to the region of interest in the bulk image (A).

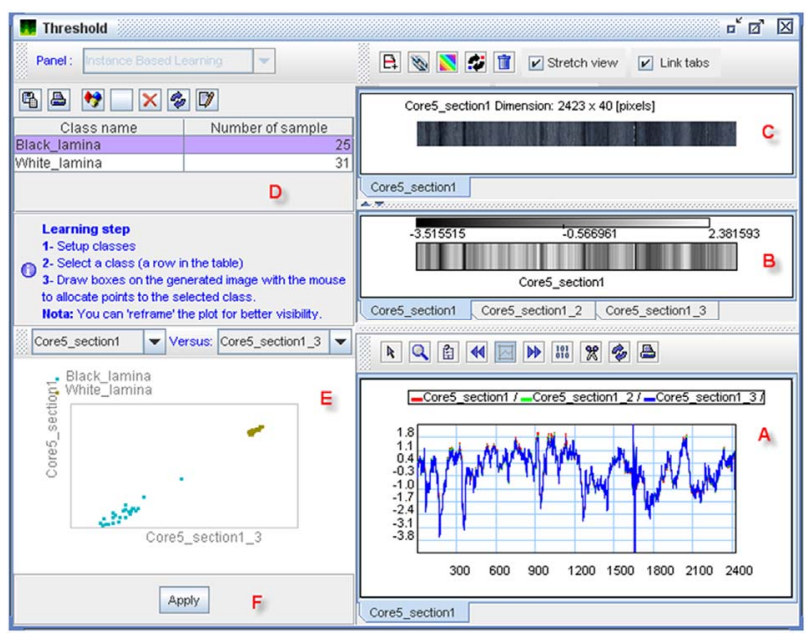

Figure 4. Example of classification window showing the extracted signals (A), a synthetic image from extracted signal (B), a crop image (C), indications on the learning step (D) and the graphic for one plane of the feature space (E).

In our example (Figure 5), a white laminae in the source image may appear in light green color in the synthetic image, otherwise it is misclassified and must be corrected manually.

There are two sources of misclassification.

The first type of misclassification, normally insignificant, is linked to the classifier. It depends on the error made by the operator during the learning step. It is evaluated by the software and indicated by the accuracy number in the classification report.

The second type of misclassification is linked to the

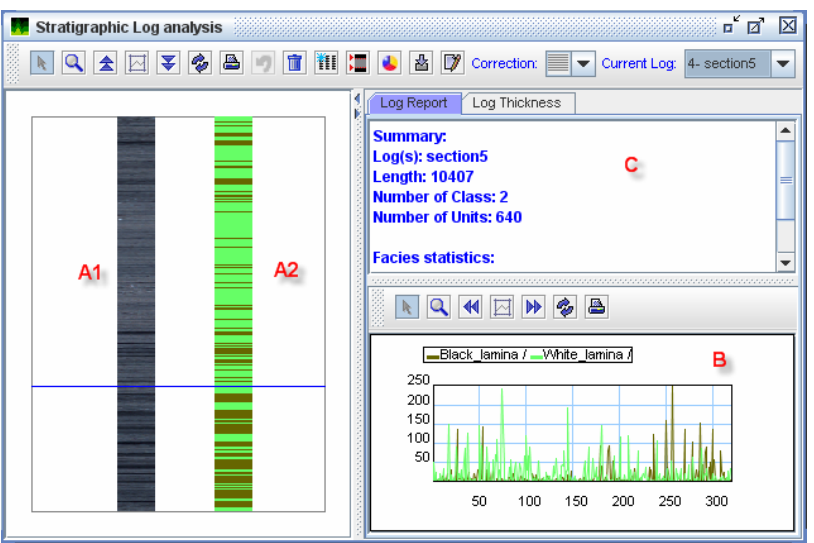

Figure 5. Results of laminae counting using K-NN. Notice the comparison between source image (A1) and synthetic image made from the classification results (A2), the report of the classification (C) and a graph corresponding to thickness variation for each type of lamina (B).

quality of the input data (e.g. absence of trend, stationarity of the input signal) and is more difficult to quantify. It can be appreciated when a high number of lamina is misclassified despite a high accuracy number in the classification report. In this case, manual correction must be used.

User-friendly tools for manual correction, when automatic classification fails, are included to overcome such difficulties. To use manual correction, one must select the type of lamina and draw it directly on the synthetic image (Figure 5(A2)).

\subsection{Varves Spectral and Wavelet Analysis}

The existence of cyclic events on the black lamina thickness signal is searched using successively spectral and wavelet analysis. Spectral analysis allows detection of existing periodicity in the signal while wavelet analysis shows, in addition to the existence of a given period, the instant it occurs [17].

Many spectral analysis methods are included in Stratisignal, but we used the classical Fourier transform in this study. For wavelet analysis, we used the Mortlet wavelet.

Spectral and wavelet analysis show periods varying slightly between 2 and 8 years. Spectral analysis (Figure 6) shows two peaks corresponding to 2 and 6 years periods. Wavelet analysis (Figure 7) confirms the existence of these two periods and shows their presence in the starting and the end of the signal.

The observed events can be linked to a forcing having a period of the same length. Torrence and Compo [18], Wang $[19,20]$ and others allocate these periods to ENSO (El Niño) phenomena. Although, it has been shown that ENSO has been active for this time interval in this area [13]. These data show by the first time that ENSO influence seems to be not continuous but punctuated. These 


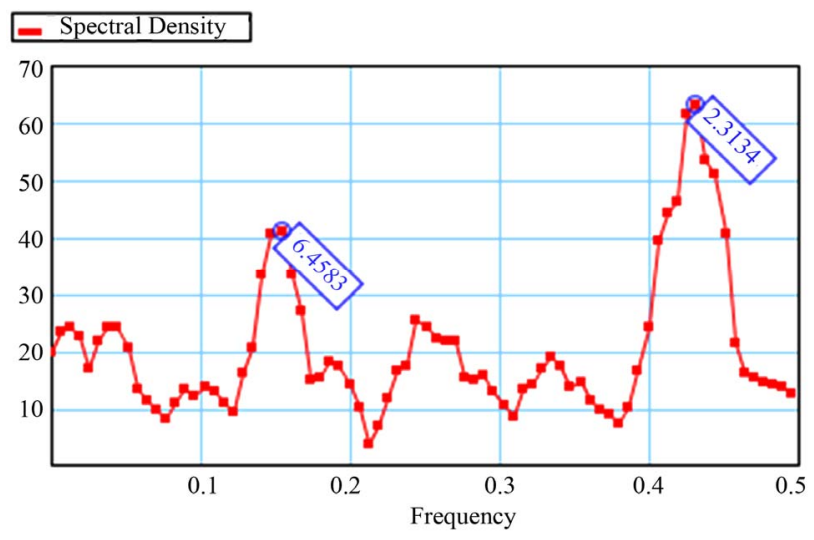

Figure 6. Fourier spectrum of black laminae signal. The periods corresponding to the main peaks are indicated in blue.
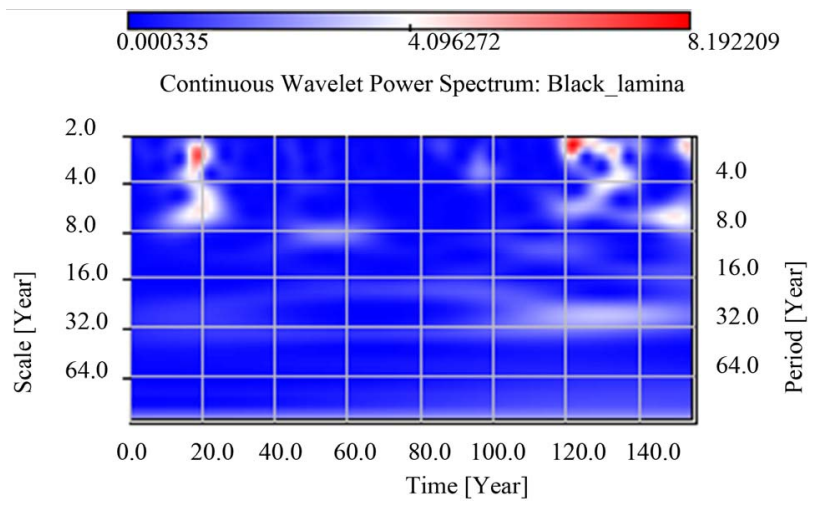

Figure 7. Wavelet analysis of black laminae signal.

intervals displaying increasing ENSO frequencies are separated by comparatively calm periods.

\section{Conclusions}

In this work we combine image analysis and signal processing methods to perform a semi-automated analysis on varved sediment. The interest of varves study, which presents annual deposition of the couplets, can be found in paleo climatology studies.

We noted that the classification step is the critical part of laminated sediments analysis as it depends on the quality of the input data. Moreover, parameters setting are widely based on empirical approach.

The methodology developed for laminated sediments analysis can be easily extended to other fields of geosciences where data present time related laminations such as stromatolites, tree rings in dendrochronology, ice cores, etc. to emphasize existence of cyclic events.

\section{Acknowledgements}

Thanks to all beta testers of Strati-signal software for their feedbacks. Thanks to Nicolas Waldmann and Adrian Gilli for the Lago Cardiel data.

\section{REFERENCES}

[1] M. Ripepe, L. T. Roberts and A. G. Fischer, "Enso and Sunspot Cycles in Varved Eocene Oil Shales from Image Analysis,” Journal of Sedimentary Research, Vol. 61, 1991, pp. 1155-1163.

[2] J. Hovikoski, M. Rasanen, M. Gingras, M. Roddaz, S. Brusset, W. Hermoza, L. R. Pittman and K. Lertola, "Miocene Semidiurnal Tidal Rhythmites in Madre de Dios, Peru,” Geology, Vol. 33, No. 3, 2005, pp. 177-180. doi:10.1130/G21102.1

[3] R. Y. Anderson, "Lacustrine Varve Formation through Time,” Paleogeography, Paleoclimatology, Paleoecology, Vol. 62, No. 1-4, 1988, pp. 215-235. doi:10.1016/0031-0182(88)90055-7

[4] G. P. Weedon, "Time-Series Analysis and Cyclostratigraphy. Examinating Stratigraphic Records of Environmental Cyles,” Cambridge University Press, Cambridge, 2003.

[5] A. J. Nederbragt, J. W. Thurow and R. B. Merrill, "Color Records from the California Margin: Proxy Indicators for Sediment Composition and Climatic Change,” Proceedings of the Ocean Drilling Program, Scientific Results, Vol. 167, 2000, pp. 319-329.

[6] U. von Rad, M. Schaaf, K. H. Michels, H. Schulz, W. H. Berger and F. Sirocko, “A 5000-yr Record of Climate Change in Varved Sediments from the Oxygen Minimum Zone off Pakistan, Northeastern Arabian Sea,” Quaternary Research, Vol. 51, No. 1, 1999, pp. 39-53. doi:10.1006/qres.1998.2016

[7] P. Francus and E. Karabanov, "A Computer-Assisted Thin-Section Study of Lake Baikal Sediments: A Tool for Understanding Sedimentary Processes and Deciphering Their Climatic Signal," International Journal of Earth Sciences, Vol. 89, No. 2, 2000, pp. 260-267. doi:10.1007/s005319900064

[8] M. C. Cooper, "The Use of Digital Image Analysis in the Study of Laminated Sediments," Journal of Paleolimnology, Vol. 19, No. 1, 1997, pp. 33-40. doi:10.1023/A:1007912417389

[9] M. Ripepe, L. T. Roberts and A. G. Fischer, "Enso and Sunspot Cycles in Varved Eocene Oil Shales from Image Analysis," Journal of Sedimentary Research, Vol. 61, 1991, pp. 1155-1163.

[10] P. Francus, F. Keimig and M. Besonen, "An Algorithm to Aid Varve Counting and Measurement from Thin-Sections,” Journal of Paleolimnology, Vol. 28, No. 2, 2002, pp. 283-286. doi:10.1023/A:1021624415920

[11] O. Weidlich and M. Bernecker, "Quantification of Depositional Changes and Paleo-Seismic Activities Next Term from Laminated Sediments Using Outcrop Data," Sedimentary Geology, Vol. 166, 2004, pp. 11-20. doi:10.1016/j.sedgeo.2003.12.004

[12] M. C. Meyer, R. Faber and C. Spotl, "The WinGeol Lamination Tool: New Software for Rapid, Semi-Automated Analysis of Laminated Climate Archives," The Holocene, Vol. 16, No. 5, 2006, pp. 753-761. doi:10.1191/0959683606hl969rr

[13] A. Gilli, D. Ariztegui, F. S. Anselmetti, J. A. McKenzie, 
V. Markgraf, I. Hajdas and R. D. McCulloch, "Mid-Holocene Strengthening of the Southern Westerlies in South America-Sedimentological Evidences from Lago Cardiel, Argentina (49 $\mathrm{S}), "$ Global and Planetary Change, Vol. 49, No. 1-2, 2005, pp. 75-93.

doi:10.1016/j.gloplacha.2005.05.004

[14] N. Waldmann, D. Ariztegui, M. Ndiaye, A. Gilli and F. S. Anselmetti, "Evidence of Late Holocene Wind Intensity Variability in Southernmost Patagonia-Lago Cardiel, Argentina," Abstracts of the Thirteenth Meeting of Swiss Sedimentologists, Fribourg, 2005.

[15] A. Gilli, F. S. Anselmetti, D. Ariztegui, J. P. Bradbury, R. Kelts Kerry, V. Markgraf and J. A. McKenzie, "Tracking Abrupt Climate Change in the Southern Hemisphere: A Seismic Stratigraphic Study of Lago Cardiel, Argentina (495)," Terra Nova, Vol. 13, No. 6, 2001, pp. 443-448. doi:10.1046/j.1365-3121.2001.00377.x

[16] B. V. Dasarathy, "Nearest Neighbor Pattern Classification Techniques,” IEEE Press, California, 1991.

[17] E. P. Verrecchia, "Multiresolution Analysis of Shell
Growth Increments to Detect Variations in Natural Cycles,” Image Analysis, Sediments and Paleoenvironments, Vol. 7, 2005, pp. 273-293. doi:10.1007/1-4020-2122-4_14

[18] C. Torrence and G. P. Compo, “A Practical Guide to Wavelet Analysis," Bulletin of the American Meteorological Society, Vol. 79, No. 1, 1998, pp. 61-78. doi:10.1175/1520-0477(1998)079<0061:APGTWA >2.0. $\mathrm{CO} ; 2$

[19] B. Wang, "Interdecadal Changes in El Niño Onset in the Last Four Decades,” Journal of Climate, Vol. 8, No. 2, 1995, pp. 267-285. doi:10.1175/1520-0442(1995)008<0267:ICIENO >2.0.CO ;2

[20] Y. Wang, "Temporal Structure of the Southern Oscillation as Revealed by Waveform and Wavelet Analysis," Journal of Climate, Vol. 9, No. 7, 1996, pp. 1586-1598. doi:10.1175/1520-0442(1996)009<1586:TSOTSO >2.0.C $\mathrm{O} ; 2$ 